\title{
A simple angle-measuring instrument for measuring cemented stem anteversion during total hip arthroplasty
}

\author{
Ryo Mitsutake $1^{1^{*}}$, Hiromasa Tanino', Yasuhiro Nishida', Masaru Higa ${ }^{2}$ and Hiroshi Ito ${ }^{1}$
}

\begin{abstract}
Background: During total hip arthroplasty (THA), the accurate placement of the femoral components is an important determinant of the success of the procedure. This study assessed the accuracy of cemented stem placement using a new angle-measuring instrument. The primary objective was to investigate the accuracy of the intraoperative measurements of cemented stem anteversion obtained using the angle-measuring instrument. Our secondary objective was to evaluate the accuracy of stem positioning performed using the angle-measuring instrument.
\end{abstract}

Methods: We compared the intraoperative stem anteversion measurements obtained using the angle-measuring instrument with postoperative stem anteversion measurements obtained using computed tomography in 149 hips (measurement accuracy). We also compared the target angle and postoperative stem anteversion in 105 hips (implantation accuracy).

Results: The mean amount of intraoperative stem anteversion was $37.9^{\circ} \pm 10.1^{\circ}$, and the mean amount of postoperative stem anteversion was $37.0^{\circ} \pm 10.4^{\circ}$. The mean measurement accuracy was $0.9^{\circ} \pm 6.1^{\circ}$, and the absolute measurement accuracy was $4.9^{\circ} \pm 3.7^{\circ}$. The correlation coefficient for the relationship between the intraoperative and postoperative stem anteversion measurements was $0.824(p=0.000)$. The mean amount of target angle was $37.4^{\circ} \pm 7.6^{\circ}$, and the mean amount of postoperative stem anteversion was $35.9^{\circ} \pm 9.1^{\circ}$. The mean implantation accuracy was $1.4^{\circ} \pm 5.6^{\circ}$, and the mean absolute implantation accuracy was $4.3^{\circ} \pm 3.6^{\circ}$. The correlation coefficient for the relationship between the target angle and postoperative stem anteversion was $0.795(p=0.000)$.

Conclusions: The angle-measuring instrument measured intraoperative stem anteversion accurately, and cemented stem was implanted accurately during THA with the angle-measuring instrument.

Keywords: Total hip arthroplasty, Stem anteversion, Angle-measuring instrument, Cemented stem

\section{Background}

During total hip arthroplasty (THA), the accurate placement of the femoral and acetabular components is an important determinant of the early and long-term success of the procedure. Poor component orientation is associated with impingement, a reduced range of motion, dislocation, and increased component wear [1-7]. Many studies have reported the optimal positions for the acetabular components, and the accuracy of acetabular

\footnotetext{
* Correspondence: mitutake@asahikawa-med.ac.jp

'Department of Orthopaedic Surgery, Asahikawa Medical University,

Midorigaoka-Higashi 2-1-1-1, Asahikawa 078-8510, Japan

Full list of author information is available at the end of the article
}

component positioning using free-hand techniques, mechanically guided techniques, or navigation systems have also been investigated [8-11]. Other studies have examined the accuracy of intraoperative measurements of stem anteversion obtained using a goniometer or navigation systems during THA [12-16]. However, only one CTbased navigation study has reported the accuracy of stem positioning during THA [17]. Moreover, no studies have reported the accuracy of stem positioning using a goniometer or mechanical guides. With cemented arthroplasty components, stem anteversion can be easily controlled by the surgeon. In contrast, in cementless arthroplasty, stem anteversion is determined by the anatomy of the femoral

(c) The Author(s). 2020 Open Access This article is distributed under the terms of the Creative Commons Attribution 4.0 International License (http://creativecommons.org/licenses/by/4.0/), which permits unrestricted use, distribution, and reproduction in any medium, provided you give appropriate credit to the original author(s) and the source, provide a link to the Creative Commons license, and indicate if changes were made. The Creative Commons Public Domain Dedication waiver (http://creativecommons.org/publicdomain/zero/1.0/) applies to the data made available in this article, unless otherwise stated. 
neck, the diaphyseal bow, and the anterior-posterior isthmus at the level of the lesser trochanter created by the calcar femorale [18]. To measure cemented stem anteversion intraoperatively during THA, we developed a simple angle-measuring instrument based on a goniometer. The primary objective of this study was to investigate the accuracy of intraoperative measurements of cemented stem anteversion obtained using the angle-measuring instrument. Our secondary objective was to evaluate the accuracy of stem positioning performed using the anglemeasuring instrument.

\section{Methods}

\section{Study population}

The study protocol was approved by our hospital's institutional review board (AMU 18183). Between August 2017 and November 2018, two experienced surgeons performed primary THA using a particular cemented femoral component in 142 patients (149 hips) at our hospital. During the same period, cementless THA was performed in patients aged $<50$ years who had goodquality femoral cortical bone. Measurement accuracy was defined as the difference between the intraoperative measurements of stem anteversion obtained using the angle-measuring instrument and the postoperative measurements of stem anteversion obtained using postoperative computed tomography (CT). The measurement accuracy of the angle-measuring instrument during the measurement of cemented stem anteversion was investigated in 149 consecutive hips (Table 1).

Table 1 Subjects' demographic data

\begin{tabular}{|c|c|c|}
\hline Parameters & $\begin{array}{l}\text { Measurement } \\
\text { accuracy }\end{array}$ & $\begin{array}{l}\text { Implantation } \\
\text { accuracy }\end{array}$ \\
\hline No. of hips/patients & 149 hips (142) & 105 hips (102) \\
\hline Sex, male/female & $26 / 116$ & $19 / 83$ \\
\hline Age (years) ${ }^{a}$ & $68.9 \pm 9.8(50-92)$ & $69.2 \pm 9.7(50-92)$ \\
\hline Height $(\mathrm{cm})^{\mathrm{a}}$ & $153.0 \pm 7.7(131-180)$ & $153.0 \pm 8.1(131-180)$ \\
\hline Weight $(\mathrm{kg})^{\mathrm{a}}$ & $56.3 \pm 11.6(33-102)$ & $55.3 \pm 11.1(33-84)$ \\
\hline Body mass index $\left(\mathrm{kg} / \mathrm{m}^{2}\right)^{a}$ & $23.9 \pm 4.3(14.7-40.2)$ & $23.5 \pm 4.1(14.7-38.3)$ \\
\hline \multicolumn{3}{|l|}{ Preoperative diagnosis } \\
\hline Osteoarthritis (OA) & 108 & 79 \\
\hline $\begin{array}{l}\text { Osteonecrosis of the } \\
\text { femoral head }\end{array}$ & 15 & 8 \\
\hline Rheumatoid arthritis & 9 & 6 \\
\hline Femoral neck fracture & 17 & 12 \\
\hline \multicolumn{3}{|l|}{ The severity of knee OA } \\
\hline grade 1 & 13 & 8 \\
\hline grade 2 & 56 & 39 \\
\hline grade 3 & 60 & 43 \\
\hline grade 4 & 20 & 15 \\
\hline
\end{tabular}

${ }^{\mathrm{a}}$ Mean \pm SD (range)
Between December 2017 and November 2018, cemented stems were implanted using the angle-measuring instrument during THA. Implantation accuracy was defined as the difference between the target stem anteversion angle and the postoperative measurements of stem anteversion obtained using postoperative CT. Each cemented stem was placed at the target angle using the angle-measuring instrument, and the implantation accuracy of the angle-measuring instrument was investigated in 105 consecutive hips (Table 1).

\section{Surgical technique and measurements}

A standard posterolateral approach was used in the lateral decubitus position in all cases. A cementless cup (Continuum Cup; Zimmer, Warsaw, IN) and a cemented stem (CMK Original Concept Stem; Zimmer, Warsaw, IN) were used in all cases. The angle-measuring instrument was attached to the handle of the femoral broach and stem, which resulted in it being aligned perpendicularly to the femoral broach and stem (Fig. 1a). The pointer of the angle meter turns upward due to gravity. The anteversion of the femoral broach and stem was measured as the angle between the gravitational direction and the line running perpendicular to the prosthetic axis (the femoral broach or stem) under $90^{\circ}$ hip flexion, maximum hip adduction, and $90^{\circ}$ knee flexion, with the tibia placed in the vertical position (Fig. 1b and c).

The acetabular side was prepared first. Our target cup position for all patients was $40^{\circ}$ abduction and $20^{\circ}$ anteversion, similar to Domb et al. [19]. And then femoral preparation was performed. Intraoperatively femoral canal was reamed and broached. All final femoral rasps used in this study for canal preparation over-rasped by $0.8 \mathrm{~mm}$ [20]. Cement was packed into the femoral canal with a cement gun, and the stem was inserted. Care was taken to insert the stem in a central position. After the stem implantation, stem anteversion was measured and measurement accuracy was investigated. The intraoperative measurements of stem anteversion were compared with postoperative measurements of stem anteversion obtained using postoperative CT to investigate measurement accuracy. All of the intraoperative measurements were performed by the same assistant surgeon.

When the final femoral broach was placed, the anglemeasuring instrument was used to measure the anteversion of the femoral broach, and the target angle was decided. A recent study reported that the intraoperative stability test, especially measuring the IR angle (the range of internal rotation under $90^{\circ}$ hip flexion and $0^{\circ}$ abduction/adduction), is a useful method for predicting hip stability after THA. An IR angle of $51^{\circ}$ was set as the cut-off point for such predictions [21]. After removing the acetabular osteophytes and femoral neck remnants, the target angle was decided by fine-tuning the femoral 
a

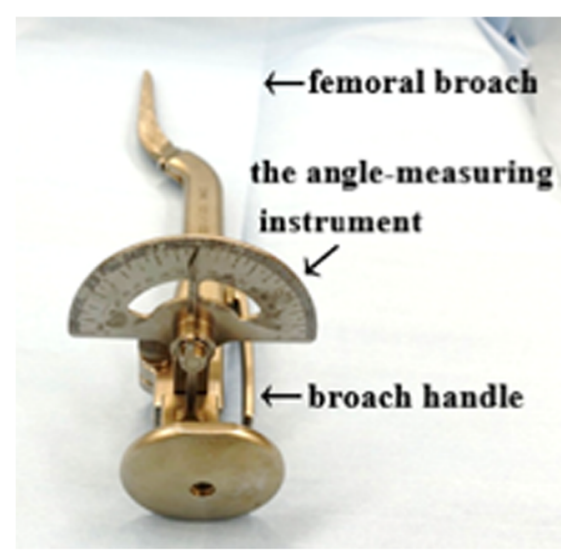

b

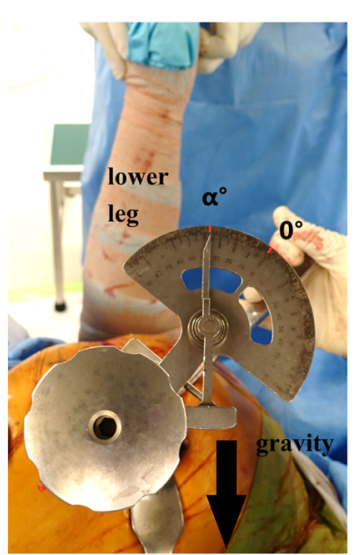

c

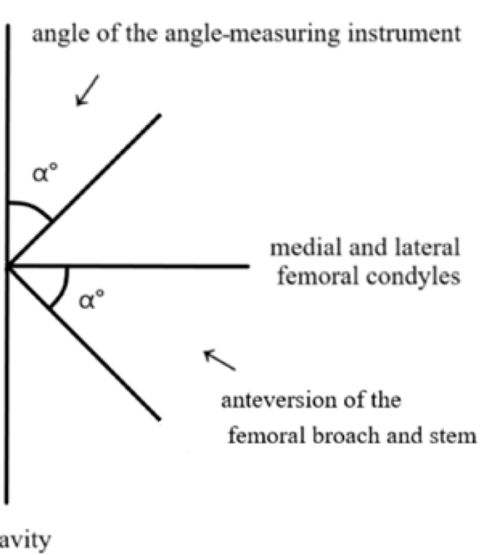

Fig. 1 a The angle-measuring instrument attached to the handle of the femoral broach. $\mathbf{b}$ The angle of the angle-measuring instrument. The angle of the angle-measuring instrument was measured as the angle between the gravitational direction and the line running perpendicular to the prosthetic axis under $90^{\circ}$ hip flexion, maximum hip adduction, and $90^{\circ}$ knee flexion, with the tibia in a vertical position. $a^{\circ}$ represents the anteversion of the femoral broach and stem. c Anteversion of the femoral broach and stem. When the tibia was placed in a vertical position, the axis passing through the medial and lateral femoral condyles ran perpendicular to the gravitational direction. The anteversion of the femoral broach and stem was determined as the angle between the prosthetic axis and the line running perpendicular to the gravitational direction. The anteversion of the femoral broach and stem reflected the angle between the gravitational direction and the line running perpendicular to the prosthetic axis. $a^{\circ}$ indicates the anteversion of the femoral broach and stem

broach and neck length to acquire an IR angle of $>51^{\circ}$ without causing anterior instability. The cemented stem was placed at the target angle using the angle-measuring instrument, and the implantation accuracy of this method was investigated.

All patients underwent similar closure procedures and postoperative care. Postoperatively, stem anteversion was measured on CT. CT were obtained on all patients 1 week after surgery. Using a Multi slice CT scanner Aquilion 64 (TSX-101A) (Canon Medical Systems Co, Japan), consecutive scans, at 2-mm intervals, were performed from the level of the fourth lumbar vertebra proximally to the knee, including the entire distal femoral condyles. Stem anteversion was determined as the angle between the stem neck axis and the axis passing through the medial and lateral femoral condyles [22, 23]. All CT-based measurements of stem anteversion were performed by the same observer, and were repeated in a blind manner during the course of two sessions, which were at least 1 month apart. Intraobserver reliability was evaluated using the intraclass correlation coefficient. In addition, two observers independently made CT-based measurements, and interobserver reliability was evaluated using the interclass correlation coefficient.

The factors studied included sex, age, body mass index (BMI), the preoperative diagnosis, and the severity of knee osteoarthritis (OA). We divided the preoperative diagnoses into two groups, the OA group and non-OA group (osteonecrosis of the femoral head, rheumatoid arthritis, or femoral neck fractures) (Table 1). Knee OA was graded according to the classification of Kellgren and Lawrence [24] and then was divided into two stages, the early stage (grade 1 or 2 ) and the advanced stage (grade 3 or 4 ) (Table 1 ).

\section{Statistical analyses}

The data are reported using descriptive statistics, including mean, standard deviation, and range values. The normality of the data was assessed using the Shapiro-Wilk test, and the paired t-test, non-parametric Mann-Whitney $\mathrm{U}$ test, and correlation analyses were performed to evaluate measurement accuracy and implantation accuracy. Univariate and multivariate linear regression analyses were conducted to analyze the potential risk factors that might affect the measurement error in measurement accuracy and implantation accuracy. $P$-values of $<0.05$ were considered significant. All statistical analyses were performed using SPSS version 25 (SPSS Inc., Chicago, IL).

\section{Results}

The mean amount of intraoperative stem anteversion, as measured using the angle-measuring instrument, was $37.9^{\circ} \pm 10.1^{\circ}$ (range: $7^{\circ}-66^{\circ}$ ), and the mean amount of postoperative stem anteversion, as measured on CT, was $37.0^{\circ} \pm 10.4^{\circ}\left(\right.$ range: $\left.7^{\circ}-64^{\circ}\right)$. The mean measurement accuracy (intraoperative stem anteversion - postoperative stem anteversion) was $0.9^{\circ} \pm 6.1^{\circ}$ (range: $-14^{\circ}-16^{\circ}$ ). The mean absolute measurement accuracy (|intraoperative stem anteversion - postoperative stem anteversion|) was $4.9^{\circ} \pm 3.7^{\circ}$ (range: $0^{\circ}-16^{\circ}$ ). The measurement accuracy was within $5^{\circ}$ in 93 hips (62\%) and within $10^{\circ}$ in 138 hips (93\%). The correlation coefficient for the relationship 
between the intraoperative and postoperative stem anteversion was $0.824(p=0.000)$ (Fig. 2). Among the factors analyzed in the univariate analyses, the severity of knee OA was found to be significantly related to measurement accuracy $(p=0.000)$. Sex, age, BMI, and the preoperative diagnosis were not found to be significantly related to measurement accuracy $(p=0.865,0.267$, 0.089 , and 0.553 , respectively). Multivariate analysis showed that the severity of knee OA significantly influenced measurement accuracy (Table 2). The mean measurement accuracy in the early stage knee OA group was $0.6^{\circ} \pm 4.5^{\circ}$ (range: $-12^{\circ}-16^{\circ}$ ), whereas it was $1.2^{\circ} \pm 7.2^{\circ}$ (range: $-14^{\circ}-16^{\circ}$ ) in the advanced stage knee OA group $(p=0.550)$. The mean absolute measurement accuracy in the early stage knee OA group was $3.3^{\circ} \pm 3.2^{\circ}$ (range: $0^{\circ}-$ $16^{\circ}$ ), whereas it was $6.2^{\circ} \pm 3.5^{\circ}$ (range: $0^{\circ}-16^{\circ}$ ) in the advanced stage knee OA group $(p=0.000)$.

The mean amount of target angle was $37.4^{\circ} \pm 7.6^{\circ}$ (range: $10^{\circ}-65^{\circ}$ ), and the mean amount of postoperative stem anteversion, as measured on $\mathrm{CT}$, was $35.9^{\circ} \pm 9.1^{\circ}$ (range: $7^{\circ}-64^{\circ}$ ). The mean implantation accuracy (target angle - postoperative stem anteversion) was $1.4^{\circ} \pm 5.6^{\circ}$ (range: $-9^{\circ}-16^{\circ}$ ). The mean absolute implantation accuracy (|target anteversion - postoperative stem anteversion $\mid$ ) was $4.3^{\circ} \pm 3.6^{\circ}$ (range: $0^{\circ}-16^{\circ}$ ). The implantation accuracy was within $5^{\circ}$ in 71 hips (68\%) and within $10^{\circ}$ in 98 hips (93\%). The correlation coefficient for the relationship between the target angle and postoperative stem anteversion was $0.795(p=0.000)$ (Fig. 3). Among the factors analyzed in the univariate analyses, age and the severity of knee OA were found to be significantly associated with implantation accuracy $(p=0.049$ and 0.000 , respectively). Sex, BMI, and the preoperative diagnosis were not found to be significantly related to implantation accuracy $(p=0.850,0.066$, and 0.267 , respectively). Multivariate analysis showed that the severity of knee $\mathrm{OA}$ significantly influenced implantation

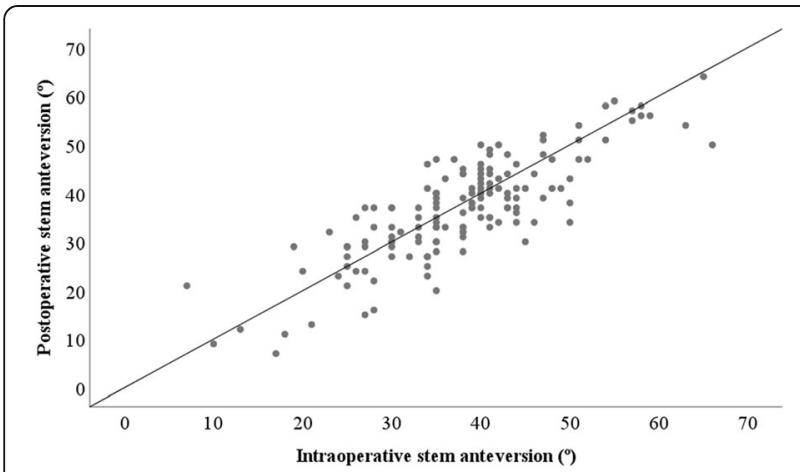

Fig. 2 The correlation between intraoperative and postoperative stem anteversion measurements. The intraoperative stem anteversion measurements exhibited a good correlation with the postoperative stem anteversion measurements (correlation coefficient: $\gamma=0.824, p=0.000$ )
Table 2 Multivariate linear regression analysis to identify factors that affect measurement accuracy

\begin{tabular}{llllll}
\hline Parameters & $\mathrm{B}$ & $\mathrm{SE}$ & $\beta$ & $\mathrm{t}$ & $P$-value \\
\hline Sex & 0.135 & 0.792 & 0.034 & 0.452 & 0.652 \\
Age & -0.034 & 0.031 & -0.009 & -0.118 & 0.906 \\
BMI & -0.118 & 0.069 & -0.119 & -1.574 & 0.118 \\
Preoperative diagnosis & 0.406 & 0.683 & 0.026 & 0.338 & 0.736 \\
Severity of knee OA & 2.883 & 0.564 & 0.388 & 5.111 & $0.000^{*}$ \\
\hline
\end{tabular}

B: unstandardized coefficient; SE: standard error; $\beta$ : standardized coefficient; ${ }^{*} p<0.05$

accuracy (Table 3). The mean implantation accuracy in the early stage knee OA group was $0.7^{\circ} \pm 3.4^{\circ}$ (range: $8^{\circ}-9^{\circ}$ ), whereas it was $2.2^{\circ} \pm 6.7^{\circ}$ (range: $-9^{\circ}-16^{\circ}$ ) in the advanced stage knee OA group $(p=0.157)$. The mean absolute implantation accuracy was $2.7^{\circ} \pm 2.6^{\circ}$ (range: $\left.0^{\circ}-9^{\circ}\right)$ in the early stage knee OA group, whereas it was $5.8^{\circ} \pm 4.0^{\circ}$ (range: $0^{\circ}-16^{\circ}$ ) in the advanced stage knee OA group $(p=0.000)$.

Excellent intraobserver reliability was seen; i.e., the intraclass correlation coefficient was 0.983 (range: 0.9770.988). In addition, excellent interobserver reliability was observed; i.e., the interclass correlation coefficient was 0.948 (range: $0.847-0.981$ ).

No intraoperative or postoperative complications related to the measurements were noted.

\section{Discussion}

We investigated the measurement accuracy of the anglemeasuring instrument for measuring the angles of cemented stems during THA and examined the accuracy of stem positioning performed using the angle-measuring instrument. The mean absolute measurement accuracy was $4.9^{\circ}$, and the mean absolute implantation accuracy was $4.3^{\circ}$. As for implantation accuracy, $68 \%$ of cases were within $5^{\circ}$, and $93 \%$ were within $10^{\circ}$.

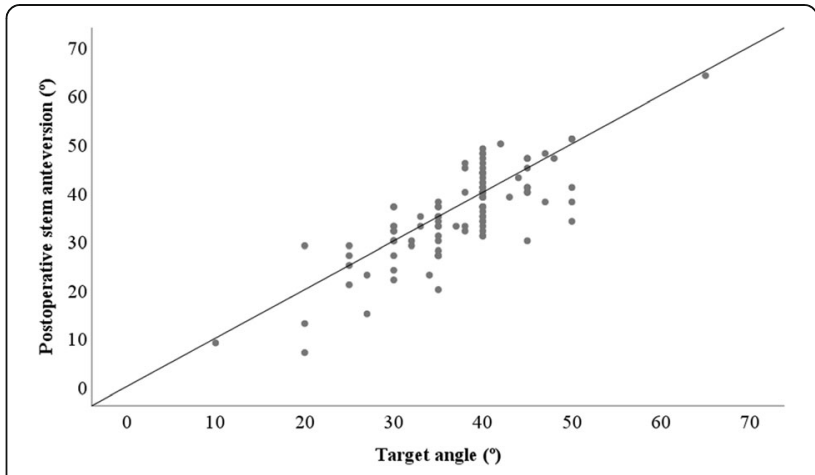

Fig. 3 The correlation between the target angle and the postoperative stem anteversion measurements. The target angle exhibited a good correlation with the postoperative stem anteversion measurements (correlation coefficient: $\gamma=0.795, p=0.000)$ 
Table 3 Multivariate linear regression analysis to identify factors that affect implantation accuracy

\begin{tabular}{llllll}
\hline Parameters & $\mathrm{B}$ & $\mathrm{SE}$ & $\beta$ & $\mathrm{t}$ & $\mathrm{p}$-value \\
\hline Sex & 0.177 & 0.934 & 0.050 & 0.558 & 0.578 \\
Age & 0.073 & 0.036 & 0.100 & 1.089 & 0.279 \\
BMl & -0.160 & 0.086 & -0.121 & -1.348 & 0.181 \\
Preoperative diagnosis & 0.925 & 0.828 & 0.079 & 0.884 & 0.087 \\
Severity of knee OA & 3.078 & 0.657 & 0.419 & 4.687 & $0.000^{*}$ \\
\hline
\end{tabular}

B: unstandardized coefficient; SE: standard error; $\beta$ : standardized coefficient; ${ }^{*} p<0.05$

Generally, the intraoperative estimation of stem anteversion is performed based on surgeons' visual assessments. Several studies have reported that there can be considerable differences between surgeons' visual assessments of stem anteversion and postoperative measurements of stem anteversion [18, 22, 25]. Wines and McNichol reported that the mean difference between surgeons' visual assessments of stem anteversion and postoperative measurements of stem anteversion was an underestimation of $1.1^{\circ}$, but the standard deviation was $10.4^{\circ}$ and a range of $25^{\circ}$ underestimation to $30^{\circ}$ overestimation. A high standard deviation means that the data were widely spread (less reliable). They believed that these differences were clinically unacceptable [22]. Dorr et al. reported that there was a weak correlation between surgeons' visual assessments of stem anteversion and postoperative measurements of stem anteversion [18]. In addition, Woerner et al. reported that the mean difference between surgeons' visual assessments of stem anteversion and postoperative measurements of stem anteversion was an underestimation of $7.3^{\circ} \pm 9.8^{\circ}$ [25].

Several studies have investigated the accuracy of measurements obtained using a goniometer or navigation systems during THA [12-16] (Table 4). They reported that the mean absolute measurement accuracy ranged from $4.5^{\circ}-7.3^{\circ}$. Thus, the mean absolute measurement accuracy value obtained in the present study $\left(4.9^{\circ}\right)$ seems to be acceptable. Several studies have reported that knee $\mathrm{OA}$ and the femorotibial angle significantly influenced measurement accuracy during THA $[13,16]$. In the current study, knee OA was shown to significantly influence measurement accuracy during THA, which is consistent with the other studies.

Only one CT-based navigation study has evaluated stem implantation accuracy during THA [17], and we could not find any clinical studies that examined stem implantation accuracy using a goniometer or mechanical guides. Kitada et al. reported that the mean target angle was $34.2^{\circ} \pm 12.4^{\circ}$, and the mean postoperative stem anteversion was $31.7^{\circ} \pm 11.7^{\circ}$. Thus, the mean implantation accuracy value was $-2.5^{\circ} \pm 6.1^{\circ}$. The absolute implantation accuracy was not reported. Our mean implantation accuracy value was $1.4^{\circ} \pm 5.6^{\circ}$, which is similar to the abovementioned value. In a previous navigation study, it was reported that stem anteversion implantation accuracy of within $5^{\circ}$ was achieved in $60 \%$ of cases. In our study, stem anteversion implantation accuracy of within $5^{\circ}$ was achieved in $68 \%$ of cases, suggesting that the angle-measuring instrument can be used to achieve accurate stem implantation. Typically, the surgical navigation systems need a large computer console, need optical sensors or magnetic sensors to track the bones and surgical tools or implant, and are expensive. Our angle-measuring instrument is simple, does not need a large computer console and sensors, is easy to use, and requires no metal fitting entry into the body compared with navigation systems. However, the stem anteversion implantation accuracy was $>5^{\circ}$ in almost $30 \%$ of cases. This suggests that the angle-measuring instrument should be used with caution, and that the instrument requires further improvement.

Improvements in our understanding of femoral morphology and anteversion and their influence on implant impingement and dislocation have caused surgeons to re-evaluate component positioning during THA [26]. Several studies have examined stem anteversion during THA [18, 27]. Dorr et al. proposed that stem anteversion should exhibit an approximate range of $10^{\circ}-20^{\circ}$, whereas D'Lima et al. stated that it should display an approximate range of $10^{\circ}-30^{\circ}$. The mean target angle in the present study was $37.4^{\circ}$. Although this was larger than those described in other studies, it was similar to some previously target angle [17]. As the present study included many cases of developmental

Table 4 Measurement accuracies reported in the literature

\begin{tabular}{|c|c|c|c|c|c|}
\hline Studies & Type & $\begin{array}{l}\text { Intraoperative stem } \\
\text { anteversion }\end{array}$ & $\begin{array}{l}\text { Postoperative stem } \\
\text { anteversion }\end{array}$ & $\begin{array}{l}\text { Mean absolute } \\
\text { measurement accuracy }\end{array}$ & Correlation coefficient \\
\hline Hirata et al. [13] & goniometer & $40.5 \pm 11.6^{\circ}$ & $34.7 \pm 11.2^{\circ}$ & $7.3 \pm 5.7^{\circ}$ & 0.798 \\
\hline Fujihara et al. [15] & goniometer & $22.7 \pm 8.4^{\circ}$ & $19.9 \pm 8.4^{\circ}$ & $4.6 \pm 4.1^{\circ}$ & \\
\hline Lee et al. [16] & goniometer & $21.5 \pm 8.5^{\circ}$ & $19.5 \pm 8.7^{\circ}$ & $4.5 \pm 2.8^{\circ}$ & 0.837 \\
\hline Hirasawa et al. [12] & CT-based navigation & & & $5.2 \pm 4.8^{\circ}$ & \\
\hline Fukunishi et al. [14] & Imageless navigation & $15.5 \pm 9.7^{\circ}$ & $20.9 \pm 10.6^{\circ}$ & $5.9 \pm 4.2^{\circ}$ & \\
\hline Current study & Angle-measuring instrument & $37.9 \pm 10.1^{\circ}$ & $37.0 \pm 10.4^{\circ}$ & $4.9 \pm 3.7^{\circ}$ & 0.824 \\
\hline
\end{tabular}


dysplasia of the hip, in which the degree of femoral anteversion was significantly large, we employed larger target angles [28]. Recently, the concept of the IR angle was reported to be a useful method for predicting hip stability after THA, and an IR angle of $51^{\circ}$ was suggested to be an appropriate cut-off point for such predictions [21]. Because a recent study reported that stem anteversion had the strongest effect on the IR angle [29], we fine-tuned stem anteversion prior to the final implantation to achieve an appropriate IR angle. Therefore, it is necessary to obtain precise intraoperative information about stem anteversion, and it is very important that surgeons are able to place cemented stems accurately during THA.

Our study had several limitations. First, it did not involve a case-control group. Second, only the posterolateral approach was examined. Danoff et al. reported that when a posterior approach is employed the cup anteversion safe zone is larger than was previously believed [30]. Thus, the optimal degree of stem anteversion might differ according to the approach employed. Third, the target angle was decided by fine-tuning the femoral broach to acquire an appropriate IR angle; however, the concept of combined anteversion has been proposed $[31,32]$. Fourth, we checked the vertical position of the tibia in visual assessment during the intraoperative measurement of stem anteversion. Although this was similar to other clinical studies [13, 16, 18, 25], it can affect the accuracy of measurements. Finally, we did not evaluate postoperative clinical outcomes; however, this was beyond the purpose of this study.

\section{Conclusions}

We developed a simple angle-measuring instrument to measure cemented stem anteversion intraoperatively and to place cemented stems accurately during THA. The measurement accuracy was $4.9^{\circ}$, that was similar to other studies with goniometer and navigation systems. And the implantation accuracy was $4.3^{\circ}$, that was similar to one navigation study. However, the stem anteversion implantation accuracy was $>5^{\circ}$ in almost $30 \%$ of cases, and the instrument requires further improvement.

\section{Abbreviations}

BMI: Body mass index; CT: Computed tomography; OA: Osteoarthritis; THA: Total hip arthroplasty

\section{Acknowledgements}

The authors declare that they have no acknowledgements to make.

\section{Authors' contributions}

The study was conceived and designed by RM and HT. Data was acquired by RM, HT, YN, and HI. RM performed the statistical analysis and drafted the manuscript. The manuscript was edited by RM, HT, YN, MH and $\mathrm{HI}$. The manuscript was reviewed and approved for final publication by all authors.

Funding

No supporting grants for this study.
Availability of data and materials

The datasets used and/or analysed in this study are available from the corresponding author on reasonable request.

\section{Ethics approval and consent to participate}

This study was approved by the Institutional Review Board of Asahikawa Medical University with reference number AMU 18183. Informed consent was obtained from all patients.

\section{Consent for publication}

Not applicable.

\section{Competing interests}

The authors declare that they have no competing interests.

\section{Author details}

${ }^{1}$ Department of Orthopaedic Surgery, Asahikawa Medical University, Midorigaoka-Higashi 2-1-1-1, Asahikawa 078-8510, Japan. ${ }^{2}$ Department of Mechanical Engineering, University of Hyogo, 2167 Shosha, Himeji 671-2280, Japan.

Received: 19 October 2019 Accepted: 17 February 2020

Published online: 19 February 2020

\section{References}

1. Lewinnek GE, Lewis JL, Tarr R, Compere CL, Zimmerman JR. Dislocations after total hip-replacement arthroplasties. J Bone Joint Surg Am. 1978;60(2): 217-20

2. Kristiansen $B$, Jørgensen $L$, Hölmich P. Dislocation following total hip arthroplasty. Arch Orthop Trauma Surg. 1985:103(6):375-7.

3. Kummer FJ, Shah S, lyer S, DiCesare PE. The effect of acetabular cup orientations on limiting hip rotation. J Arthroplast. 1999;14(4):509-13.

4. Patil S, Bergula A, Chen PC, Colwell CW Jr, D'Lima DD. Polyethylene wear and acetabular component orientation. J Bone Joint Surg Am. 2003;85A(Suppl 4):56-63.

5. Widmer $\mathrm{KH}$, Zurfluh B. Compliant positioning of total hip components for optimal range of motion. J Orthop Res. 2004:22(4):815-21.

6. Yoshimine F. The safe-zones for combined cup and neck anteversions that fulfill the essential range of motion and their optimum combination in total hip replacements. J Biomech. 2006;39(7):1315-23.

7. Mayeda BF, Haw JG, Battenberg AK, Schmalzried TP. Femoral-Acetabular Mating: The Effect of Femoral and Combined Anteversion on Cross-Linked Polyethylene Wear. J Arthroplast. 2018;33(10):3320-4.

8. Digioia AM 3rd, Jaramaz B, Plakseychuk AY, Moody JE Jr, Nikou C, Labarca RS, Levison TJ, Picard F. Comparison of a mechanical acetabular alignment guide with computer placement of the socket. J Arthroplast. 2002;17(3): 359-64.

9. Dorr LD, Malik A, Wan Z, Long WT, Harris M. Precision and bias of imageless computer navigation and surgeon estimates for acetabular component position. Clin Orthop Relat Res. 2007:465:92-9.

10. Ecker TM, Tannast M, Murphy SB. Computed tomography-based surgical navigation for hip arthroplasty. Clin Orthop Relat Res. 2007 Dec;465:100-5.

11. Tanino $H$, Nishida $Y$, Mitsutake R, Ito H. Portable Accelerometer-Based Navigation System for Cup Placement of Total Hip Arthroplasty: A Prospective, Randomized, Controlled Study. J Arthroplast. 2020;35(1):172-7.

12. Hirasawa N, Matsubara M, Ishii K, Hagio S, Okuda N, Sekiya I, Muneta T. Effect of CT slice thickness on accuracy of implant positioning in navigated total hip arthroplasty. Comput Aided Surg. 2010;15(4-6):83-9.

13. Hirata M, Nakashima Y, Ohishi M, Hamai S, Hara D, Iwamoto Y. Surgeon error in performing intraoperative estimation of stem anteversion in cementless total hip arthroplasty. J Arthroplast. 2013;28(9):1648-53.

14. Fukunishi S, Nishio S, Fujihara Y, Okahisa S, Takeda Y, Fukui T, Yoshiya S. Accuracy of combined anteversion in image-free navigated total hip arthroplasty: stem-first or cup-first technique? Int Orthop. 2016;40(1):9-13.

15. Fujihara Y, Fukunishi S, Fukui T, Nishio S, Okahisa S, Takeda Y, Kurosaka K, Yoshiya S. Use of the G-guide for Measuring Stem Antetorsion During Total Hip Arthroplasty. Orthopedics. 2016;39(2):e271-5

16. Lee YK, Kim JW, Kim TY, Ha YC, Koo KH. Validity of the intra-operative measurement of stem anteversion and factors for the erroneous estimation in cementless total hip arthroplasty using postero-lateral approach. Orthop Traumatol Surg Res. 2018;104(3):341-6. 
17. Kitada M, Nakamura N, Iwana D, Kakimoto A, Nishii T, Sugano N. Evaluation of the accuracy of computed tomography-based navigation for femoral stem orientation and leg length discrepancy. J Arthroplast. 2011;26(5):674-9.

18. Dorr LD, Wan Z, Malik A, Zhu J, Dastane M, Deshmane P. A comparison of surgeon estimation and computed tomographic measurement of femoral component anteversion in cementless total hip arthroplasty. J Bone Joint Surg Am. 2009;91(11):2598-604

19. Domb BG, Redmond JM, Louis SS, Alden KJ, Daley RJ, LaReau JM, Petrakos AE, Gui C, Suarez-Ahedo C. Accuracy of Component Positioning in 1980 Total Hip Arthroplasties: A Comparative Analysis by Surgical Technique and Mode of Guidance. J Arthroplast. 2015;30(12):2208-18.

20. Ito H, Hirayama T, Tanino H, Matsuno T, Minami A. Tight fit technique in primary hybrid total hip arthroplasty for patients with hip dysplasia. J Arthroplast. 2007;22(1):57-64.

21. Tanino H, Sato T, Nishida Y, Mitsutake R, Ito H. Hip stability after total hip arthroplasty predicted by intraoperative stability test and range of motion: a cross-sectional study. BMC Musculoskelet Disord. 2018;19(1):373.

22. Wines AP, McNicol D. Computed tomography measurement of the accuracy of component version in total hip arthroplasty. J Arthroplast. 2006; 21(5):696-701.

23. Reikerås $\mathrm{O}$, Gunderson RB. Components anteversion in primary cementless THA using straight stem and hemispherical cup: a prospective study in 91 hips using CT-scan measurements. Orthop Traumatol Surg Res. 2011;97(6): 615-21.

24. Kellgren JH, Lawrence JS. Radiological assessment of osteo-arthrosis. Ann Rheum Dis. 1957;16(4):494-502

25. Woerner M, Sendtner E, Springorum R, Craiovan B, Worlicek M, Renkawitz T, Grifka J, Weber M. Visual intraoperative estimation of cup and stem position is not reliable in minimally invasive hip arthroplasty. Acta Orthop. 2016;87(3): 225-30.

26. Lum ZC, Coury JG, Cohen JL, Dorr LD. The Current Knowledge on Spinopelvic Mobility. J Arthroplast. 2018;33(1):291-6.

27. D'Lima DD, Urquhart AG, Buehler KO, Walker RH, Colwell CW Jr. The effect of the orientation of the acetabular and femoral components on the range of motion of the hip at different head-neck ratios. J Bone Joint Surg Am. 2000;82(3):315-21.

28. Argenson JN, Ryembault E, Flecher X, Brassart N, Parratte S, Aubaniac JM. Three-dimensional anatomy of the hip in osteoarthritis after developmental dysplasia. J Bone Joint Surg (Br). 2005;87(9):1192-6.

29. Tanino H, Ito H, Nishida Y, Yamanaka Y, Nakamura T, Matsuno T. Component positions affect in vivo stability of Total hip Arthroplasty. Orthop Res Soc. 2012;942 https://www.ors.org/abstract-search/.

30. Danoff JR, Bobman JT, Cunn G, Murtaugh T, Gorroochurn P, Geller JA, Macaulay W. Redefining the Acetabular Component Safe Zone for Posterior Approach Total Hip Arthroplasty. J Arthroplast. 2016;31(2):506-11.

31. Jolles BM, Zangger P, Leyvraz PF. Factors predisposing to dislocation after primary total hip arthroplasty: a multivariate analysis. J Arthroplast. 2002; 17(3):282-8.

32. Nakashima Y, Hirata M, Akiyama M, Itokawa T, Yamamoto T, Motomura $G$, Ohishi M, Hamai S, Iwamoto Y. Combined anteversion technique reduced the dislocation in cementless total hip arthroplasty. Int Orthop. 2014;38(1): 27-32.

\section{Publisher's Note}

Springer Nature remains neutral with regard to jurisdictional claims in published maps and institutional affiliations.

\section{Ready to submit your research? Choose BMC and benefit from:}

- fast, convenient online submission

- thorough peer review by experienced researchers in your field

- rapid publication on acceptance

- support for research data, including large and complex data types

- gold Open Access which fosters wider collaboration and increased citations

- maximum visibility for your research: over $100 \mathrm{M}$ website views per year

At BMC, research is always in progress.

Learn more biomedcentral.com/submissions 